\title{
Correction to: Does type of robotic platform make a difference in the final cost of robotic-assisted radical prostatectomy?
}

\author{
Marcio Covas Moschovas ${ }^{1,4}$ (1) Talia Helman $^{2} \cdot$ Seetharam Bhat ${ }^{1} \cdot$ Marco Sandri $^{3} \cdot$ Travis Rogers $^{1} \cdot$ Jonathan Noel $^{1}$. \\ Sunil Reddy ${ }^{1}$. Cathy Corder ${ }^{1} \cdot$ Vipul Patel ${ }^{1,4}$
}

Published online: 25 February 2022

๑) Springer-Verlag London Ltd., part of Springer Nature 2022

Correction to: Journal of Robotic Surgery

https://doi.org/10.1007/s11701-021-01359-5

The original version of this article unfortunately contained a mistake. In abstract, the last sentence should read as

In our experience, the lack of GelPOINT and space maker are also crucial factors to decrease the SP total cost.

In conclusion, second sentence should read as

The use of GelPOINT and space maker are crucial factors to increase the SP total cost even more.

Publisher's Note Springer Nature remains neutral with regard to jurisdictional claims in published maps and institutional affiliations.

The original article can be found online at https://doi.org/10.1007/ s11701-021-01359-5.

Marcio Covas Moschovas

marcio.doc@hotmail.com

1 AdventHealth Global Robotics Institute, 410 Celebration

Place Suite \#200, Celebration, FL 34747, USA

2 University of Central Florida College of Medicine, Orlando,

FL, USA

3 Big and Open Data Innovation Laboratory (BODaI-Lab),

University of Brescia, Brescia, Italy

4 University of Central Florida (UCF), Florida, Orlando, USA 